\title{
Comparison of the effect of Chamomile and Mefenamic Acid on primary dysmenorrhea, associated symptoms and menstrual bleeding - A randomized clinical trial study
}

Fatemeh Shabani

Arak University of Medical Sciences

Katayon Vakilian

Arak University of Medical Sciences

Fereshteh Narenji

Arak University of Medical Sciences

Mahbubeh Bozorgi

Tehran University of Medical Sciences

Soodabeh Bioos

Tehran University of Medical Sciences

Fatemeh Nejatbakhsh ( $\square$ nejatbakhsh@tums.ac.ir)

Tehran University of Medical Sciences

Research article

Keywords: Medicinal Plant, Chamomile, Honey, Primary Dysmenorrhea, Pain

Posted Date: July 22nd, 2020

DOI: https://doi.org/10.21203/rs.3.rs-40277/v1

License: (1) (7) This work is licensed under a Creative Commons Attribution 4.0 International License. Read Full License 


\section{Abstract \\ Background}

Dysmenorrhea is one of the most common pelvic pains in women, impairing their quality of life.This study investigated the effects of chamomile sachet and mefenamic acid on primary dysmenorrhea, associated symptoms and bleeding.

\section{Methods}

In this randomized clinical trial, 200 female students with primary dysmenorrhea from Arak universities were randomly assigned to two groups. The group (A) received mefenamic acid (250 $\mathrm{mg})$ and group (B) received chamomile $(5000 \mathrm{mg}$ ) plus one teaspoonful of honey )as a flavoring ( for two days before up to the first three days of menstruation, three times a day in two consecutive cycles. Pain severity, associated symptoms and bleeding were assessed using visual analog scale, Andersch-Milsom Verbal Scale and Higham chart, respectively. Data were analyzed by descriptive and inferential statistical tests by SPSS 21 .

\section{Results}

Severe pain during two months after intervention was in $6(6.3 \%)$ of group (B) and $6(6.3 \%)$ in group (A) (p $=0.351, p=0.332)$. Mean severity of associated symptoms two months after the treatment was $(4.93 \pm$ $3.54)$ in group (B) and $(5.62 \pm 3.54)$ in group $(A)$, indicating further reduction in group (B) but not significant $(p=0.278)$. Mean of bleeding was (88.71 $\pm 66.4 \mathrm{vs.} 70.54 \pm 53.34)$ in group (B) and $(A)$ respectively, in two months later. therefore decrease in the two groups but was not significant between groups $(p=0.567)$.

\section{Conclusions}

It seems chamomile sachet can reduce the severity of pain and bleeding similar to mefenamic acid and even further mitigate the symptoms associated with dysmenorrhea.

\section{Trial registration:}

This study was performed with the proposal approval code of 2611, ethics code of (ARAKMU.REC.1395.164) at Arak University of medical sciences and code of IRCT 2016100825031N5 on 2016.11.08.

\section{Background}

Primary dysmenorrhea is one the most common problems for young girls. It is associated with painful menstruation without a pathologic cause beginning with crampy abdominal pain shortly before 
menstruation and lasting up to 72 hours. However, considering the increasing secretion of prostaglandin in the first 48 hours of menstruation, the highest intensity of pain occurs at this time (1). In studies conducted regarding the prevalence of primary dysmenorrhea in young women, varying degrees of pain $(60-90 \%)$ have been reported (2); nevertheless, the severity of pain in a number of patients is so severe to interfere with daily activities, which is a leading cause of absenteeism from school and work $(3,4)$.

With the detection of excessive E2 and F2a prostaglandin levels in the endometrium of women with primary dysmenorrhea, initial dysmenorrhea appears to result from the overproduction of PGF2a or the increase in the ratio of PGF2 $a$ to PGE2. Prostaglandins can cause severe uterine contractions, fatigue, dizziness, headache, nervous change and other related symptoms (5-7). There are several treatments for primary dysmenorrhea and associated symptoms, including contraceptive pills $(8,9)$, vitamin E compounds (10), vitamin D (10-12), fish oil supplements (13), diet (14), exercise and physical activity (15), acupuncture (16), topical heat (17), psychotherapy (18) and Nonsteroidal anti-inflammatory drugs (NSAIDs).

NSAIDs have a special place in suppressing inflammation due to decreasing the levels of prostaglandins (19). These drugs lead to a significant decrease in PG concentration in endometrial fluid and a decrease in uterine tone by inhibiting cyclooxygenase. Mefenamic acid is a common NSAID but cause a range of adverse effects such as diarrhea, stomachache, and nausea to serious illness such as chronic renal disease and osteoporosis (20). Nowadays, complications of chemical drugs have shifted the attention of people and researchers to complementary therapies $(21,22)$.

Chamomile plants, namely Chamomilla recutita and Matricaria Chamomilla, have a positive effect on dysmenorrhea due to anti-inflammatory activity (23). The use of chamomile reduces abdominal and pelvic pain, fatigue, lethargy and depression during menstrual cycles (24). The ethanolic extract from the flowers of this plant has anti-inflammatory, anti-spasmodic, anti-anxiety and sedative effects (25). Although US Food and Drug Administration states that chamomile has no side effects on pregnancy, lactation or on children, researchers have recommended further studies on the side effects and benefits of complementary medicine (26-27).

There have been several studies on the efficacy of chamomile along with mefenamic acid, indicating that chamomile has been as effective as mefenamic acid in reducing pain but the effect of chamomile on menstrual bleeding has shown different results. Also, there have been few studies on symptoms associated with dysmenorrhea (28), thus the need for further studies with different forms and doses of chamomile with more people living in different places, and comparison with safe drugs is felt to confirm previous results or find new results of chamomile effects on dysmenorrhea and its symptoms $(22,28-34)$.

The goal of this research is to compare the effect of chamomile sachet with mefenamic acid capsule on primary dysmenorrhea, associated symptoms and the volume of menstrual bleeding.

\section{Methods}

\section{Study design}


The present study is a double blind randomized clinical trial conducted on 200 female students fromfour universities in Arak in 2018. The city of Arak has six universities and sampling was performed by draw from four universities.

\section{Study participants}

The study was conducted on 200 female students. The inclusion criteria were as follows: single students with moderate to severe menstruation pain (score four or higher of pain intensity according to visual analog scale, age range of 18-30 years, initiation of menstruation pain before 20 years of age, regular menstruation cycles with intervals of 21-35 days, menstrual bleeding without passing clots (low and moderate bleeding), onset and duration of menstruation from a few hours before menstruation up to day 5 of bleeding. Other criteria were lack of chronic diseases, no consumption of drugs such as anticoagulants, oral contraceptives, benzodiazepines, narcotics, lack of regular exercise, abnormal vaginal discharge, history of allergy to herbs, stressors in the last two months, special dietary requirements, history of pelvic inflammatory disease, myoma and pelvic tumors, history of gynecological surgery, transfer to another university and graduation within the next six months.

The exclusion criteria were as follows: patients' desire to leave the study, having any disease requiring prolonged or continuous medication, dietary supplements and vitamins, reluctance to continue taking the drug on their own for any reason, failure to complete the pain severity table and other questionnaire items, incidence of stressful conditions over the past two months, history of contraceptive use, undergoing any surgery during the study, getting married over the study period, changing the place of residence and not consuming the drugs according to the protocol failure to complete questionnaire .

\section{Sample size}

Sample size was calculated 45 students in each group based on confidence interval of $95 \%$, power of $80 \%$ and minimum average difference score (d) of 0.5 . Due to insufficient quantity of medication and other consumables, the number of samples reached 90 , and 100 participants were assigned to each group after adding a possible attrition rate of $10 \%$.

The following formula was used to calculate the sample size:

$$
\mathrm{N}=\frac{\left(\mathrm{z}_{1}+z_{2}\right)^{2} \times\left(2 \mathrm{~s}^{2}\right)}{\mathrm{d}^{2}}=45
$$

\section{Study procedure}

After obtaining the approval of University Ethics Committee and IRCT code as well as receiving a letter from Arak University of Medical Sciences that was presented to the heads of Arak universities, , the researcher referred to the universities for sampling. Announcements were made for students with menstrual pain. By referring students, researcher, study aim and execution method fully explained. The checklist, which included demographic information, midwifery, entry and exit requirements, was given to individuals and 
how to fill out a checklist, especially the pain scale, was taught.After completing the checklist, students who were eligible to enter the project were randomly invited to collaborate according to the sample size.

Out of 350 participants (from a total of 1200), 200 students eligible to enter the project who were willing to cooperate were chosen after submitting written informed consent forms. The subjects were randomly divided into two groups of mefenamic acid (group A) and chamomile sachet (group B) using random blocks. The contents were enclosed in envelopes of the same shape and then the blinding was done. The willingness of the company to conduct research and keep the information confidential was emphasized for the research units.

The researcher again described the research procedure to the subjects and an emphasis was put on precise use of medication and correct completion of questionnaire(especially measuring intensity of pain, complete the table bleeding and determining the severity of associated symptoms).In addition, the address and phone number of the researcher was given to students for their follow-up.

To comply with the ethical considerations for pain relief, volunteers could use other dwellings if they did not have pain control and should record the exact type and number of dwellings accurately.

Medications for each group as well as sanitary pads with medium size from the same brand without absorbent material were given to students to measure the amount of menstrual bleeding in the preintervention cycle as well as two consecutive interventional cycles.

The sachet for the chamomile contained $5000 \mathrm{mg}$ of chamomile and a spoonful of honey was consumed per serving. Due to the bitter taste of chamomile, honey was used in small amounts only as a flavoring with sachet of chamomile to improve its taste. Studies show that therapeutic doses of honey can be effective in treating dysmenorrhea $(35,36)$. The sachet contents were gently boiled in a glass of water for three minutes, filtered and dissolved in a spoonful of honey and were then ingested.

On the other hand, $250 \mathrm{mg}$ mefenamic acid capsules were administered to the subjects in the mefenamic group. The two groups received the same instruction for two days before menstruation up to three days after it and three daily servings for two consecutive cycles. The researcher followed up the timely and correct consumption of medicinal plants and mefenamic acid and was also associated with students in cyberspace. In this study, five subjects in chamomile sachet and four subjects of mefenamic acid group did not continue participation in the study (Figure 1).

\section{Study procedure}

After obtaining the approval of University Ethics Committee and IRCT code as well as receiving a letter from Arak University of Medical Sciences that was presented to the heads of Arak universities, , the researcher referred to the universities for sampling. Announcements were made for students with menstrual pain. By referring students, researcher, study aim and execution method fully explained. The checklist, which included demographic information, midwifery, entry and exit requirements, was given to individuals and 
how to fill out a checklist, especially the pain scale, was taught.After completing the checklist, students who were eligible to enter the project were randomly invited to collaborate according to the sample size.

Out of 350 participants (from a total of 1200), 200 students eligible to enter the project who were willing to cooperate were chosen after submitting written informed consent forms. The subjects were randomly divided into two groups of mefenamic acid (group A) and chamomile sachet (group B) using random blocks. The contents were enclosed in envelopes of the same shape and then the blinding was done. The willingness of the company to conduct research and keep the information confidential was emphasized for the research units.

The researcher again described the research procedure to the subjects and an emphasis was put on precise use of medication and correct completion of questionnaire(especially measuring intensity of pain, complete the table bleeding and determining the severity of associated symptoms).In addition, the address and phone number of the researcher was given to students for their follow-up.

To comply with the ethical considerations for pain relief, volunteers could use other dwellings if they did not have pain control and should record the exact type and number of dwellings accurately.

Medications for each group as well as sanitary pads with medium size from the same brand without absorbent material were given to students to measure the amount of menstrual bleeding in the preintervention cycle as well as two consecutive interventional cycles.

The sachet for the chamomile contained $5000 \mathrm{mg}$ of chamomile and a spoonful of honey was consumed per serving. Due to the bitter taste of chamomile, honey was used in small amounts only as a flavoring with sachet of chamomile to improve its taste. Studies show that therapeutic doses of honey can be effective in treating dysmenorrhea $(35,36)$. The sachet contents were gently boiled in a glass of water for three minutes, filtered and dissolved in a spoonful of honey and were then ingested.

On the other hand, $250 \mathrm{mg}$ mefenamic acid capsules were administered to the subjects in the mefenamic group. The two groups received the same instruction for two days before menstruation up to three days after it and three daily servings for two consecutive cycles. The researcher followed up the timely and correct consumption of medicinal plants and mefenamic acid and was also associated with students in cyberspace. In this study, five subjects in chamomile sachet and four subjects of mefenamic acid group did not continue participation in the study (Figure 1).

\section{Data collection tools}

Data collection was done by a questionnaire in three times. Questionnaire No. 1,2 and 3 were completed by research units before intervention, one and two months after the intervention, respectively. The questionnaire consisted of demographic information, investigating pain intensity and duration using pain ruler, menstrual blood loss was evaluated using a pictorial chart and accompanying symptoms of dysmenorrhea were assessed using the Andersch-Milsom verbal scale. 
The intensity of dysmenorrhea pain was assessed by Visual Analog Scale (VAS) and 8-10, 4-7, and 1-3 scores represented severe, moderate, and mild pain, respectively. Pictorial Bleeding Assessment Loss Chart (PBAC) was employed to determine the extent of bleeding, indicating an estimate of the blood loss through menstruation with mild (score 1), moderate (score 5), and severe (score 20) criteria on a sanitary pad. In this chart, small quantity of blood on sanitary pads was given score 1 , the large ones score 5 , and impregnation with blood score 20. The chart also rated small and large clots. Small clots scored 1, large clots 5 , and flow of blood scored 10 . A score $<50$ indicated mild bleeding, 51-100 moderate bleeding, and $>100$ hypermenorrhea during menstruation. The scores were summed up to calculate the overall score. The symptoms related with dysmenorrhea were measured based on Andersch-Milsom Verbal Multidimensional Scoring System. Four grades have been mentioned in this scale for the severity of dysmenorrhea symptoms as follows: score 0 (no symptoms); score 1 (mild symptoms are present but do not interfere with daily activities); score 2 (symptoms exist and interfere with daily tasks but are moderate and not debilitating; score 3 (symptoms are quite debilitating and severe (15).

\section{Isolation of essential oil}

$500 \mathrm{~g}$ of chamomile flower was hydro distilled for $12 \mathrm{~h}$ in a Clevenger type apparatus to isolate the essential oils Thenwere stored in dark conditions at $-4^{\circ} \mathrm{C}$ for $\mathrm{GC} /$ Mass analyses.

Gas chromatography-mass spectrometry was done by Perkin-Elmer autosystem XL GC equipped with ZB5 capillary column ( $5 \%$ phenyl-95\% dimethyl polysiloxane, $30 \mathrm{~mm} \times 0.25 \mathrm{~mm} \times 0.25 \mu \mathrm{m}$ ). The mobile phase was helium gas with flow rate of $1 \mathrm{ml} / \mathrm{min}$.

\section{Statistical analysis}

Analysis of collected data was done using SPSS software through descriptive statistics of percentage and mean as well as analytical statistics including Mann-Whitney $U$, Wilcoxon, repeated measure ANOVA and $\mathrm{X} 2$ tests.

\section{Ethical consideration}

This study was performed with the proposal approval code of 2611, ethics code of (ARAKMU.REC.1395.164) at Arak University of medical sciences and code of IRCT 2016100825031N5. All the ethics principles of the Helsinki Charter were observed in the study. After submitting a letter to the research institution and the participants, the researcher obtained written consent from the volunteer participants.

\section{Results}

\section{Chemical composition of essential oil}

As a result of GC/MS analysis for chamomile oil, a-Bisabolol oxide was found to be the main constituent $(34 \%)$, followed by chamazulene (12\%), 1,8-cineole ( $8 \%)$, and limonene (5\%) as the major compounds. 


\section{Demographic characteristics}

The demographic and midwifery characteristics of subjects evaluated by Kruskal-Wallis test )age, menarche, age of dysmenorrhea onset), Fisher's exact test and chi-square test (education level, menstruation cycle, length of menstruation bleeding per day, and regular menstruation) are shown in Table 1.

Table 1

The characteristics of research samples in the chamomile and mefenamic acid groups ${ }^{1}$

\begin{tabular}{|c|c|c|c|c|}
\hline & & $\begin{array}{l}\text { Mefenamic } \\
\text { acid }\end{array}$ & $\begin{array}{l}\text { chamomile } \\
\mathrm{N}(\%)\end{array}$ & $\begin{array}{l}P- \\
\text { value }\end{array}$ \\
\hline & & \multicolumn{3}{|l|}{$N(\%)$} \\
\hline \multirow[t]{5}{*}{ Level of education } & $\begin{array}{l}\text { Associate } \\
\text { degree }\end{array}$ & $9(9.4)$ & 4. $(4.2)$ & \multirow[t]{5}{*}{0.106} \\
\hline & $\begin{array}{l}\text { Bachelor's } \\
\text { degree }\end{array}$ & $82(85.4)$ & $83(87.5)$ & \\
\hline & $\begin{array}{l}\text { Master's } \\
\text { degree }\end{array}$ & $1(1)$ & $6(7.3)$ & \\
\hline & PhD & $3(3.2)$ & $2(1)$ & \\
\hline & GP & $1(1)$ & 0 & \\
\hline \multirow{3}{*}{$\begin{array}{l}\text { The length of the menstruation bleeding } \\
\text { (day) }\end{array}$} & 3 & $3(3.1)$ & $3(3.1)$ & \multirow[t]{3}{*}{0.114} \\
\hline & $4-7$ & 78(81.3) & $86(90 / 6)$ & \\
\hline & 7 & $15(15.6)$ & $6(6.3)$ & \\
\hline \multirow[t]{2}{*}{ Regular menstruation } & Yes & $82(85.4)$ & $76(80.2)$ & \multirow[t]{2}{*}{0.329} \\
\hline & No & $14(14.6)$ & 19(19.8) & \\
\hline \multirow[t]{4}{*}{ Menstruation Cycle } & 21 & $12(12.5)$ & 11(11.6) & \multirow[t]{3}{*}{0.593} \\
\hline & $22-35$ & $83(86.5)$ & $84(88.4)$ & \\
\hline & $>35$ & $1(1)$ & 0 & \\
\hline & & Mean & Mean(23) & \\
\hline $\begin{array}{l}\text { Age } \\
\text { (Mean } \pm \text { Standard deviation) }\end{array}$ & & $20.88(1.74)$ & $21.5(2.24)$ & 0.145 \\
\hline $\begin{array}{l}\text { Menarche } \\
\text { (Mean } \pm \text { Standard deviation) }\end{array}$ & & 13.1(1.48) & $13.35(1.3)$ & 0.323 \\
\hline $\begin{array}{l}\text { Beginning age of Dysmenorrhea } \\
\text { (Mean } \pm \text { Standard deviation) }\end{array}$ & & $15.46(2.36)$ & $15.05(2.18)$ & 0.258 \\
\hline
\end{tabular}


1. mean with using Kruskal-Wallis) Age ,Menarche, Beginning age of Dysmenorrhea).

frequently distribution with using Fisher exact test and chi-square test(Level of education, Menstruation Cycle, The length of the menstruation bleeding (day), Regular menstruation)

\section{Symptoms of dysmenorrhea}

The results of Friedman test showed a significant decrease in the severity of pain one and two months after treatment in group A $(p=0.001)$ and in group $B(p=0.001)$ and Fisher's exact test results indicated that the frequency distribution of pain intensity within one $(p=0.351)$ and two months $(p=0.332)$ of treatment was no significantly different in the two groups $(P=0.001)$ (Table 2$)$.

Table 2

Comparing the frequency distribution of the intensity of pain across three times in the chamomile and mefenamic acid groups ${ }^{2}$

\begin{tabular}{|c|c|c|c|c|c|}
\hline \multirow[t]{3}{*}{ Intervention } & \multirow[t]{3}{*}{$\begin{array}{l}\text { Pain } \\
\text { severity }\end{array}$} & $\begin{array}{l}\text { Before } \\
\text { intervention }\end{array}$ & $\begin{array}{l}\text { One month } \\
\text { later }\end{array}$ & $\begin{array}{l}\text { Two month } \\
\text { later }\end{array}$ & $\begin{array}{l}\text { P value } \\
\text { (Friedman) }\end{array}$ \\
\hline & & $\mathbf{N}$ & $\mathbf{N}$ & $\mathbf{N}$ & \\
\hline & & $(\%)$ & $(\%)$ & $(\%)$ & \\
\hline \multirow{4}{*}{$\begin{array}{l}\text { Mefenamic } \\
\text { acid }\end{array}$} & 0 & 0 & $3(3.2)$ & $4(4.2)$ & \multirow[t]{4}{*}{0.001} \\
\hline & $1-3$ & 0 & $44(45.8)$ & $51(53)$ & \\
\hline & $4-7$ & $50(52.1)$ & $39(40.6)$ & $35(36.5)$ & \\
\hline & $8-10$ & $46(47.9)$ & $10(10.4)$ & $6(6.3)$ & \\
\hline \multirow[t]{5}{*}{ Chamomile } & 0 & 0 & $8(8.3)$ & $10(10.4)$ & \multirow[t]{4}{*}{0.001} \\
\hline & $1-3$ & 0 & $36(37.5)$ & $44(45.8)$ & \\
\hline & $4-7$ & $44(45.8)$ & $43(44.8)$ & $36(37.5)$ & \\
\hline & $8-10$ & $52(54.2)$ & $9(9.4)$ & $6(6.3)$ & \\
\hline & & 0.470 & 0.351 & 0.332 & $\begin{array}{l}\text { P value } \\
\text { (Fisher) }\end{array}$ \\
\hline
\end{tabular}

${ }^{2}$ Friedman test and Fisher test

The results of repeated measures ANOVA test within group showed mean score of pain days $(p<0.05)$, mean Higham score $(p=0.0001, F=20.02)$, mean changes associated symptoms of dysmenorrhea $(p=$ $0.005, F=5.47$ ) in both groups had significant difference and the results of paired comparisons Bonferroni 
test showed that changes in scores of associated symptoms in both groups were significant up to one month after the intervention (Table 3).

Results of between-group repeated measure test with control for confounding effects (age of dysmenorrhea) showed that there was no significant difference in mean score of the number of pain days $(p=0.248, F=1.371)$, the mean score of associated symptoms $(p=0.278, F=1.183)$ and score of Hingham with confounding effect (Hingham score in baseline and age of dysmenorrhea) $(p=0.567, F=0.329)$ (Table 3).

Table 3

Comparison of the Mean of pain days, mean value of associated symptoms of dysmenorrhea, mean of bleeding in the chamomile and mefenamic acid groups ${ }^{3}$.

\begin{tabular}{|c|c|c|c|c|c|c|c|c|}
\hline \multirow[t]{2}{*}{ Variable } & \multirow[t]{2}{*}{ group } & \multirow[t]{2}{*}{$\begin{array}{l}\text { Baseline } \\
\text { mean } \pm \\
\text { SD }\end{array}$} & \multirow{2}{*}{$\begin{array}{l}\text { One } \\
\text { month } \\
\text { later } \\
\text { mean } \\
\pm S D\end{array}$} & \multirow[t]{2}{*}{$\begin{array}{l}\text { Two } \\
\text { month } \\
\text { later } \\
\text { mean } \\
\pm \text { SD }\end{array}$} & \multicolumn{3}{|c|}{$\begin{array}{l}\text { Repeated measure test } \\
\text { (pairwise comparisons } \\
\text { bonferroni) }\end{array}$} & \multirow[t]{2}{*}{$\begin{array}{l}\text { Repeated } \\
\text { measure } \\
\text { test } \\
\text { (between } \\
\text { group) }\end{array}$} \\
\hline & & & & & $0-1$ & $0-2$ & $1-2$ & \\
\hline \multirow[t]{2}{*}{$\begin{array}{l}\text { pain days in } \\
\text { dysmenorrhea }\end{array}$} & Chamomile & $\begin{array}{l}2.43 \pm \\
0.98\end{array}$ & $\begin{array}{l}1.86 \pm \\
0.7\end{array}$ & $\begin{array}{l}1.82 \pm \\
0.57\end{array}$ & 0.0001 & 0.0001 & 0.310 & \multirow{3}{*}{$\begin{array}{l}F=1.371 \\
\text { pvalue }= \\
0.248\end{array}$} \\
\hline & $\begin{array}{l}\text { Mefenamic } \\
\text { acid }\end{array}$ & $\begin{array}{l}2.31 \pm \\
0.98\end{array}$ & $\begin{array}{l}1.79 \pm \\
0.8\end{array}$ & $\begin{array}{l}1.70 \pm \\
0.73\end{array}$ & 0.005 & 0.0001 & 0.165 & \\
\hline P-value & & 0.605 & 0.510 & 0.3 & & & & \\
\hline \multirow[t]{2}{*}{$\begin{array}{l}\text { symptoms of } \\
\text { dysmenorrhea }\end{array}$} & Chamomile & $\begin{array}{l}7.22 \pm \\
3.78\end{array}$ & $\begin{array}{l}5.41 \pm \\
3.98\end{array}$ & $\begin{array}{l}4.93 \pm \\
3.54\end{array}$ & 0.0001 & 0.0001 & 0.127 & \multirow{3}{*}{$\begin{array}{l}F=1.183 \\
\text { pvalue }= \\
0.278\end{array}$} \\
\hline & $\begin{array}{l}\text { Mefenamic } \\
\text { acid }\end{array}$ & $\begin{array}{l}7.62 \pm \\
3.97\end{array}$ & $\begin{array}{l}6.18 \pm \\
3.8\end{array}$ & $\begin{array}{l}5.62 \pm \\
3.54\end{array}$ & 0.0001 & 0.0001 & 0.05 & \\
\hline P-value & & 0.464 & 0.108 & 0.162 & & & & \\
\hline \multirow[t]{2}{*}{$\begin{array}{l}\text { Higham } \\
\text { (PBAC) }\end{array}$} & Chamomile & $\begin{array}{l}101.85 \\
\pm 67.38\end{array}$ & $\begin{array}{l}89.72 \\
\pm \\
63.61\end{array}$ & $\begin{array}{l}88.71 \\
\pm 66.4\end{array}$ & 0.119 & 0.0001 & 0.312 & \multirow{3}{*}{$\begin{array}{l}F=0.329 \\
\text { pvalue }= \\
0.567\end{array}$} \\
\hline & $\begin{array}{l}\text { Mefenamic } \\
\text { acid }\end{array}$ & $\begin{array}{l}109.06 \\
\pm 72.84\end{array}$ & $\begin{array}{l}82.49 \\
\pm \\
58.89\end{array}$ & $\begin{array}{l}70.54 \\
\pm \\
53.34\end{array}$ & 0.291 & 0.325 & 0.297 & \\
\hline P-value & & 0.743 & 0.263 & 0.131 & & & & \\
\hline
\end{tabular}

${ }^{3}$.Mean of pain days : between groups (between group repeated measure test)

Mean of pain days : within-group (repeated measures within-group test).

Mean mean value of associated symptoms of dysmenorrhea : between groups (between group repeated measure test) . 
Mean value of associated symptoms of dysmenorrhea :within-group (repeated measures within-group test,then Bonferroni test).

Mean Hingham scores: between groups (between group repeated measure test)

Mean Hingham scores: within-group (repeated measures within-group test,then Bonferroni test).

Comparison of each of the associated symptoms in detail using Friedman test revealed that although the mean severity of associated symptoms in chamomile sachet group was reduced to a higher extent than the mefenamic acid group, no significant statistical relationship was found in this difference one and two months after the treatment $(p=0.262$ and $p=0.131$, respectively). Symptoms such as headache, back pain, diarrhea, dizziness, fatigue and anorexia in sachet of chamomile group showed a higher reduction in average intensity $(p=0.001)$. Moreover, the mean intensity of symptoms such as vomiting, fainting and mood changes had a higher reduction in the mefenamic acid group but was not significant (Table 4). 
Table 4

Comparison of mean value of associated symptoms of dysmenorrhea in chamomile and mefenamic acid groups $^{4}$

\begin{tabular}{|c|c|c|c|c|}
\hline & & Chamomile & $\begin{array}{l}\text { Mefenamic } \\
\text { acid }\end{array}$ & \\
\hline \multirow[t]{4}{*}{ Back pain } & $\begin{array}{l}\text { Before the } \\
\text { intervention }\end{array}$ & $1.91 \pm 1.01$ & $1.86 \pm 0.88$ & 0.563 \\
\hline & One month later & $\begin{array}{l}1.218 \pm \\
0.92\end{array}$ & $1.28 \pm 0.84$ & 0.802 \\
\hline & Two month later & $1.08 \pm 0.91$ & $1.17 \pm 0.8$ & 0.479 \\
\hline & & 0.001 & 0.001 & \\
\hline \multirow[t]{4}{*}{ Vomiting } & $\begin{array}{l}\text { Before the } \\
\text { intervention }\end{array}$ & $\begin{array}{l}0.364 \pm \\
0.727\end{array}$ & $0.531 \pm 0.983$ & 0.508 \\
\hline & One month later & $\begin{array}{l}0.250 \pm \\
0.68\end{array}$ & $0.343 \pm 0.83$ & 0.515 \\
\hline & Two month later & $\begin{array}{l}0.187 \pm \\
0.62\end{array}$ & $0.229 \pm 0.73$ & 0.873 \\
\hline & & 0.006 & 0.001 & \\
\hline \multirow[t]{4}{*}{ Diarrhea } & $\begin{array}{l}\text { Before the } \\
\text { intervention }\end{array}$ & $\begin{array}{l}0.531 \pm \\
0.75\end{array}$ & $0.281 \pm 0.67$ & 0.02 \\
\hline & One month later & $\begin{array}{l}0.437 \pm \\
0.85\end{array}$ & $0.208 \pm 0.52$ & 0.074 \\
\hline & Two month later & $\begin{array}{l}0.333 \pm \\
0.57\end{array}$ & $0.25 \pm 0.63$ & 0.057 \\
\hline & & 0.001 & 0.487 & \\
\hline \multirow[t]{4}{*}{ Dizziness } & $\begin{array}{l}\text { Before the } \\
\text { intervention }\end{array}$ & $\begin{array}{l}0.468 \pm \\
0.69\end{array}$ & $0.572 \pm 0.86$ & 0.726 \\
\hline & One month later & $\begin{array}{l}0.281 \pm \\
0.59\end{array}$ & $0.479 \pm 0.78$ & 0.044 \\
\hline & Two month later & $0.25 \pm 0.56$ & $0.416 \pm 0.73$ & 0.094 \\
\hline & & 0.001 & 0.019 & \\
\hline \multirow[t]{4}{*}{ Headache } & $\begin{array}{l}\text { Before the } \\
\text { intervention }\end{array}$ & $\begin{array}{l}0.291 \pm \\
0.56\end{array}$ & $0.593 \pm 0.77$ & 0.004 \\
\hline & One month later & $\begin{array}{l}0.187 \pm \\
0.49\end{array}$ & $0.531 \pm 0.78$ & 0.0001 \\
\hline & Two month later & $\begin{array}{l}0.167 \pm \\
0.46\end{array}$ & $0.479 \pm 0.69$ & 0.001 \\
\hline & & 0.013 & 0.007 & \\
\hline
\end{tabular}




\begin{tabular}{|c|c|c|c|c|}
\hline & & Chamomile & $\begin{array}{l}\text { Mefenamic } \\
\text { acid }\end{array}$ & \\
\hline \multirow[t]{4}{*}{ Anorexia } & $\begin{array}{l}\text { Before the } \\
\text { intervention }\end{array}$ & $\begin{array}{l}0.708 \pm \\
0.76\end{array}$ & $0.479 \pm 0.66$ & 0.031 \\
\hline & One month later & $\begin{array}{l}0.583 \pm \\
0.73\end{array}$ & $0.333 \pm 0.6$ & 0.01 \\
\hline & Two month later & $\begin{array}{l}0.562 \pm \\
0.72\end{array}$ & $0.364 \pm 0.58$ & 0.059 \\
\hline & & 0.187 & 0.01 & \\
\hline \multirow[t]{4}{*}{ Fainting } & $\begin{array}{l}\text { Before the } \\
\text { intervention }\end{array}$ & $\begin{array}{l}0.239 \pm \\
0.55\end{array}$ & $0.291 \pm 0.7$ & 0.879 \\
\hline & One month later & $0.25 \pm 0.64$ & $0.26 \pm 0.6$ & 0.723 \\
\hline & Two month later & $0.22 \pm 0.53$ & $0.229 \pm 0.58$ & 0.652 \\
\hline & & 0.962 & 0.05 & \\
\hline \multirow[t]{4}{*}{ Fatigue } & $\begin{array}{l}\text { Before the } \\
\text { intervention }\end{array}$ & $1.5 \pm 0.84$ & $1.447 \pm 0.99$ & 0.881 \\
\hline & One month later & $\begin{array}{l}1.145 \pm \\
0.84\end{array}$ & $1.312 \pm 0.97$ & 0.247 \\
\hline & Two month later & $1.08 \pm 0.84$ & $1.197 \pm 0.87$ & 0.426 \\
\hline & & 0.001 & 0.006 & \\
\hline \multirow[t]{4}{*}{ Mood changes } & $\begin{array}{l}\text { Before the } \\
\text { intervention }\end{array}$ & $\begin{array}{l}1.218 \pm \\
0.93\end{array}$ & $1.562 \pm 1.06$ & 0.029 \\
\hline & One month later & $0.93 \pm 0.91$ & $1.43 \pm 1.05$ & 0.001 \\
\hline & Two month later & $1.02 \pm 0.94$ & $1.28 \pm 0.94$ & 0.067 \\
\hline & & 0.001 & 0.001 & \\
\hline \multirow[t]{4}{*}{$\begin{array}{l}\text { The total score of associated } \\
\text { symptoms }\end{array}$} & $\begin{array}{l}\text { Before the } \\
\text { intervention }\end{array}$ & $7.22 \pm 3.98$ & $7.62 \pm 3.97$ & 0.743 \\
\hline & One month later & $5.41 \pm 3.07$ & $6.18 \pm 3.8$ & 0.262 \\
\hline & Two month later & $4.93 \pm 3.54$ & $5.62 \pm 3.54$ & 0.131 \\
\hline & & 0.001 & 0.001 & \\
\hline
\end{tabular}

${ }^{4}$ Friedman test

Overall, the reported side effects of mefenamic acid users included gastrointestinal complications $(n=9)$ and the complaint in the chamomile group was bitter taste and vomiting $(n=5)$. 


\section{Discussion}

The present study showed that chamomile and mefenamic acid both reduced pain intensity, duration of pain and bleeding equally, chamomile appears to be more successful in alleviating the symptoms associated with dysmenorrhea.

Research shows that a-Bisabolol and its oxides in the flowers of chamomile have therapeutic value. Chamomile has antispasmodic, anti-inflammatory, antihistamine, antioxidant, and anti-anxiety properties. Due to the presence of flavonoids and alkaloids with direct effect in the reduction of prostaglandins, active ingredients such as spiroether, namely a strong antispasmodic agent ,also having the ability to block the calcium channel, chamomile can relieve the pain during the menstruation and prevent premature delivery. On the other hand, it seems that chamomile suppresses pain through the effect of Matrisin, Metoxicomarin, Flavonoids, Phytostrogenic and Apigenin on central nervous system (37-42).

Other studies have reported the reduced amount bleeding of chamomile same to other drugs such as mefenamic acid, ginger and fennel, and the decrease of bleeding between chamomile and the drugs mentioned did not differ significantly $(43,25)$; however, no information is available on its mechanism of action (44).

one of the most likely factors causing severe menstrual bleeding has been reported to be an increase in the production of uterine prostaglandins. PGE2 and PGF2a increase blood flow to the uterus and E2 prostaglandins are vasodilators, thus elevating the risk of menstrual bleeding. Several researches have shown that the inhibition of prostaglandin synthesis can decrease the amount of menstrual bleeding in women. Since chamomile has anti-prostaglandin properties, it inhibits cyclooxygenase and stops the production of prostaglandins and leukotrienes $(28,31)$

According to traditional medicine, dysmenorrhea occurs due to the cold and the concentration of substances in the uterus, which requires a drug that is warm and able to relieve the cold as well as eliminating the concentration of substances $(45,46)$. Chamomile has a hot and dry temperament and is able to relieve uterine coldness; moreover, it is soluble and can alleviate the concentration and help relieve dysmenorrhea and its associated bleeding (47). Karimian et al. performed a clinical trial on 90 female students with primary dysmenorrhea. In this study, one group received $250 \mathrm{mg}$ chamomile capsules and the other group took mefenamic acid capsules $250 \mathrm{mg}$ every 8 hours from 48 hours before menstruation to 24 hours after it, which was administered in two cycles. The results showed that chamomile is as effective as mefenamic acid in relieving dysmenorrhea and that the amount of bleeding decreased in the two groups (33). Study of Radfard showed that chamomile reduced the severity and duration of pain during menstruation similar to yarrow (37) and in Modarres study, severity of pain and mean hemorrhage score decreased with chamomile that considerably alleviated pain (28).

Results of Najafi's study comparing bleeding amount between chamomile capsules or placebo using Higham chart showed the average bleeding in the chamomile group decreased after its consumption (31). Abedian showed that the bleeding was reduced in both groups of chamomile and mefenamic acid (44). The results of the present study using chamomile as a sachet before the onset of menstruation (Due to 
chamomile is more effective on relieving dysmenorrhea if it is used before pain begins) (25) are consistent with other studies with capsule, drop, tea, and different amounts of chamomile $(25,48,22)$. In a study to compare the effects of chamomile extract and mefenamic acid on PMS, Sharifi reported complications of chamomile increasing bleeding, that may be due to the type and concentration of active ingredients in chamomile in different places of cultivation and different seasons of the year and needs more study.

Examination of changes in symptoms associated with primary dysmenorrhea in this study showed that the mean severity of signs such as back pain, diarrhea, dizziness, headache, anorexia and fatigue was further decreased in chamomile group, and the difference was significant in relation to the headache symptom. Studies show that chamomile in addition to antispasmodic and anti-inflammatory properties, is a stimulant factor of central nervous system. Apigenin, glycine, luteolin and flavonoids found in chamomile bind benzodiazepine receptors and have anxiolytic and sedative effects and are effective for stress and anxiety relief $(37,38,49,50)$. It seems that chamomile can be used to treat nightmares and other sleep disorders (50). Dysmenorrhea is associated with neurological symptoms and it is predicted that the consumption of chamomile will improve the quality of sleep and reduce fatigue.

In addition, due to the sedative effects of chamomile, a person's mental state as well as mood disorders such as irritability is likely to improve (51-53). In the study of Janabi on primary dysmenorrhea, menstrual pain, anxiety and emotions in the chamomile tea group had a significant difference from the control group (25). Yazdani showed that the consumption of fennel and chamomile had a significant effect on dysmenorrhea and on the three symptoms of premenstrual syndrome abdominal and pelvic pain, fatigue, lethargy, and depression with anger. Chamomile has been shown to be more effective in relieving abdominal and pelvic pain, depression, anger, and fennel is more effective in reducing fatigue and lethargy (48). Dadfar showed that chamomile extract reduced the severity of PMS anxiety, depressive symptoms and retention symptoms; however, it had no effect on physical and emotional symptoms (49). In another study, the physical symptoms were decreased to the same degree by chamomile extract and mefenamic acid and the decrease in psychological symptoms by chamomile was more pronounced than mefenamic acid. It was concluded that flavonoids, apigenin and luteolin in chamomile have anti-anxiety and sedative effects, while mefenamic acid has anti-prostaglandin effects (34). The reason for the difference in the results as previously mentioned, could be due to the difference in the method of preparation of the drug and its effect on the active ingredients.In this research, gastrointestinal complications occurred in those taking mefenamic acid and although other studies show improved gastrointestinal complications using chamomile, it caused vomiting symptoms in our study. It seems that bitter taste of chamomile sachet leads to low digestive tolerance and vomiting in these individuals. Researchers suggest the combination of chamomile and honey for treatment of dysmenorrhea and further studies and long-term trial studies with a larger number of participants are necessary to ensure the definitive effectiveness of herbal remedies.

\section{Conclusions}

The results of the study showed that chamomile sachet was effective in reducing pain and symptoms associated with primary dysmenorrhea and menstrual bleeding similar to mefenamic acid capsules. It is

Page 15/22 
recommended that midwives and reproductive health professionals use complimentary methods in clinical fields and suggest them as treatment options according to the needs of women.

\section{Limitation}

A limitation of this study was self-assessment. The method of completing the questionnaire was fully explained to the subjects and in all stages of the study, the researcher was in contact with the research units. Also, it was not possible to completely simulate plant compounds with mefenamic acid. Attempts were made to minimize the effects of disruptive factors such as immeasurable stress and consumption of tea, coffee, and salt through randomization. Appropriate sample size was used to reduce the selection error, and blinding was performed to reduce the error of data interpretation.

\section{Abbreviations}

PGF2 $a$, PGE2

prostaglandin $\mathrm{F} 2 \mathrm{a}$, prostaglandin E2

NSAIDs

Nonsteroidal anti-inflammatory drugs

VAS

Visual Analog Scale

PBAC

Pictorial Bleeding Assessment Loss Chart( Higham chart)

\section{Declarations}

\section{Ethics approval and consent to participate}

This study was performed with the proposal approval code No. 2611 and ethics code No.

IR.ARAKMU.REC.1395.164 and IRCT code No. 2016100825031N5 at Arak University of Medical Sciences in Iran.

\section{Consent for publication}

Written and informed consent has been obtained from all the students.

\section{Availability of data and materials}

The source of data and materials will not be shared because we are working on another related research topic and are preparing to publish it.

\section{Competing interests}

There was no conflict of interest between the authors as well as with Traditional Medicine School of Tehran University providing the combined sachet. 


\section{Funding}

This study was funded with the proposal approval code No. 2611 at Arak University of Medical Sciences in Iran.

\section{Authors' contributions}

Sh F, NB F, BM, and B S designed the study. Sh F,N F and VC conducted the study and Sh F, NB F,N F,BM and VC analyzed and interpreted results and wrote and approved the final manuscript. Sh F, NB F supervised the project. All authors read and approved the final manuscript.

NB F, agrees to be held accountable for all aspects of this work.

\section{Acknowledgements}

The researchers highly appreciate the Complementary Research Center of Arak University of Medical Sciences and all the students and other people who cooperated in this research.

\section{References}

1. De Sanctis V, Soliman AT, Elsedfy H, Soliman NA, Elalaily R, El Kholy M. Dysmenorrhea in adolescents and young adults: a review in different countries. Acta Biomed. 2016;87(3):233-46.

2. Davood Abadi M, Vakilian K, Seyyed Zadeh Aghdam N, Ranjbaran M. The Effect of Valerian and Ginger on Dysmenorrhea: A Randomized Clinical Trial. International Journal of Women's Health and Reproduction Sciences 2020;8(1):101-6.

3. Hailemeskel S, Demissie D, Assefa N. Primary dysmenorrhea magnitude, associated risk factors, and its effect on academic performance: evidence from female university students in Ethiopia. International Journal of Women's Health. 2016;8:489-96.

4. Kural M, Noor NN, Pandit D, Joshi T, Patil A. Menstrual characteristics and prevalence of dysmenorrhea in college going girls. Journal of family medicine and primary care.2015;4(3):426.

5. Janatan B. Berek \& Novak's gynecology. 15 e, editor. Philadelphia: Lippincott Williams \& Wilkins; 2016.

6. Hertz H, Leukotriene L, Score VVA. Gabriele Tridenti and Cristina Vezzani. Good Practice in Pediatric and Adolescent Gynecology. 2017:77.

7. Alsaleem MA. Dysmenorrhea, associated symptoms, and management among students at King Khalid University, Saudi Arabia: An exploratory study. Journal of family medicine and primary care. 2018;7(4):769.

8. Uysal G, Akkaya H, Cagli F, Tutus S, Tayyar AT. A comparison of two different oral contraceptives in patients with severe primary dysmenorrhoea. Journal of Obstetrics and Gynaecology. 2018;38(6):828- 
32.

9. Wong $\mathrm{CL}$, Farquhar $\mathrm{C}$, Roberts $\mathrm{H}$, Proctor M. Oral contraceptive pill as treatment for primary dysmenorrhoea. Cochrane Database of Systematic Reviews. 2009.

10. Pakniat $H$, Chegini V, Ranjkesh F, Hosseini MA. Comparison of the effect of vitamin $E$, vitamin $D$ and ginger on the severity of primary dysmenorrhea: a single-blind clinical trial. Obstetrics \& gynecology science. 2019;62(6):462-8.

11. Lama A, Najla A, Azzah A, Areej A, Alaa E, Salem A. Vitamin D Supplements as Adjunctive Therapy with Analgesics for Primary Dysmenorrhea: A Randomized Clinical Trial. 2019.

12. Moini A, Ebrahimi T, Shirzad N, et al. The effect of vitamin D on primary dysmenorrhea with vitamin $D$ deficiency: a randomized double-blind controlled clinical trial. Gynecological Endocrinology. 2016;32(6):502-5.

13. Zafari M, Behmanesh F, Mohammadi AA. Comparison of the effect of fish oil and ibuprofen on treatment of severe pain in primary dysmenorrhea. Caspian journal of internal medicine. 2011;2(3):279.

14. Kartal YA, Akyuz EY. The effect of diet on primary dysmenorrhea in university students: A randomized controlled clinical trial. Pakistan journal of medical sciences. 2018;34(6):1478.

15. Matthewman G, Lee A, Kaur JG, Daley AJ. Physical activity for primary dysmenorrhea: a systematic review and meta-analysis of randomized controlled trials. American journal of obstetrics and gynecology. 2018;219(3):255. e1-. e20.

16. Woo HL, Ji HR, Pak YK, et al. The efficacy and safety of acupuncture in women with primary dysmenorrhea: a systematic review and meta-analysis. Medicine. 2018;97.

17. Jo J, Lee SH. Heat therapy for primary dysmenorrhea: A systematic review and meta-analysis of its effects on pain relief and quality of life. Scientific reports. 2018 ;8(1):16252. doi: 10.1038/s41598-01834303-z.

18. Elboim-Gabyzon M, Kalichman L. Transcutaneous Electrical Nerve Stimulation (TENS) for Primary Dysmenorrhea: An Overview. International Journal of Women's Health. 2020;12:1.

19. Feng $X$, Wang $X$. Comparison of the efficacy and safety of non-steroidal anti-inflammatory drugs for patients with primary dysmenorrhea: A network meta-analysis. Molecular pain. 2018;14:1744806918770320.

20. Daily J, Zhang X, Kim D, Park S. Efficacy of ginger for alleviating the symptoms of primary dysmenorrhea: a systematic review and meta-analysis of randomized clinical trials. Pain Medicine. 2015;16(12):2243-55. 
21. Leem J, Jo J, Kwon C, Lee H, Sun Park K, Lee J. Herbal medicine (Hyeolbuchukeo-tang or Xuefu Zhuyu decoction) for treating primary dysmenorrhea: A systematic review and meta-analysis of randomized controlled trials. Medicine. 2019;98.

22. Samadi N, Amani F, Taghizadeh M, Alahyari I, Ghazalbash S, Kazemzadeh R. Effect of Using Combination of Fennel, Chamomile and Ginger on Relieving Symptoms of Primary Dysmenorrheal among Students in Ardabil University of Medical Sciences in 2012. Scientific Journal of Ilam University of Medical Sciences. 2015;22(6):159-64.

23. Madunić J, Madunić IV, Gajski G, Popić J, Garaj-Vrhovac V. Apigenin: A dietary flavonoid with diverse anticancer properties. Cancer Letters. 2018;413:11-22.

24. Azmodeh E, Nasrin. F. Dysmenorrhea and its Treatment with Chemical Drugs and Components of Complementary Medicine Overview. Research Journal of Sabzevar University of Medical Sciences Student Research Committee. 2010;14.

25. Jenabi E, Samira E. Effect of Chamomile Tea on Primary Dysmenorrhea. the Iranian Journal of Obstetrics, Gynecology and fertility. 2010;13(1):39-42.

26. Ataolahi M, Sedigheh A. Primary Dysmenorrhea and Complementary Medicine. Journal of Shahid Beheshti School of Nursing and Midwifery. 2014;23(83):65-74.

27. Aksu H, Özsoy S. Primary dysmenorrhea and herbals. Journal of Healthcare Communications. 2016;1(3):23.

28. Modares M, Mirmohamadali M, Ashire Z, Mehran A. Comparison of the Effect of Mefenamic Acid and Matricaria Camomilla Capsules on Primary Dysmenorrhea. Babol Medical Science University Journal. $2010 ; 13$.

29. Saei Gharenaz M. Effect of medicinal plants in the treatment of primary dysmenorrhea in Iran: a review article. The Iranian Journal of Obstetrics, Gynecology and Infertility. 2015;18(160):14-31.

30. M N. Maintaining health from the perspective of traditional Iranian medicine. ranian Traditional Medicine Publications. 2013.

31. Mollabashi EN, Ziaie T, Bekhradi R, Khalesi ZB. Do Chamomile effect on duration, amount of bleeding, and interval of menstrual cycles? Journal of Pharmacopuncture. 2020;23(1):25.

32. Najafi Mollabashi E, Ziaie T, Bostani Khalesi Z, Kazemnejad Leili E, Bekhradi R. Effect of Chamomile capsule on premenstrual syndrome symptoms relief. The Iranian Journal of Obstetrics, Gynecology and Infertility. 2018;21(7):72-80.

33. Karimian Z, Sadat Z, Abedzadeh M, Sarafraz N, Kafaeiatrian M, Bahrami N. Comparison of the effects of chamomile capsule and mefenamic acid capsule on the severity of primary dysmenorrhea Students 
of Kashan University of Medical Sciences. Medical Journal Of Ardebil Medical Sciene. 2013;13(4):41420.

34. Sharifi F, Simbar M, Mojab F, Alavi Majd H. A Comparative Study of the Effects of Matricaria Chamomilla Extract and Mefenamic Acid on the Severity of Premenstrual Syndrome Symptoms. Journal of Arak University of Medical Sciences. 2013;16(1):71-8.

35. Mirbagher Ajorpaz N, Hafezi M, Salehi So, Tayebi A, shenasa F,Zahtabechi F.Comparing the effect of pure and impure honey on severity of pain,amount of bleeding, and duration and interval of menstrual cyclesin female students with primary dysmenorrhea. Evidence Based Care Quarterly. 2013;2(2):23-33.

36. Farahani ËLA, Hasanpoor-Azghdy SB, Kasraei H, Heidari T. Comparison of the effect of honey and mefenamic acid on the severity of pain in women with primary dysmenorrhea. Archives of gynecology and obstetrics. 2017;296(2):277-83.

37. Radfar S, Shahoie R, Noori B, Jalilian F, Nasab LH. Comparative Study on the Effect of Matricaria chamomile and Achillea millefolium Capsules on Primary Dysmenorrhea Intensity of Dormitory Students of Kurdistan University of Medical Sciences. Journal of Pharmaceutical Research International. 2018:1-7.

38. Khalesi ZB, Beiranvand SP, Bokaie M. Efficacy of Chamomile in the Treatment of Premenstrual Syndrome: A Systematic Review. Journal of Pharmacopuncture. 2019;22(4):204.

39. Bahmani M, Eftekhari Z, Jelodari M, Saki K, Abdollahi R, Majlesi M, et al. Effect of Iranian herbal medicines in dysmenorrhea phytotherapy. Journal of Chemical and Pharmaceutical Research. 2015(2):519-26.

40. Goel B, Maurya NK. Overview on: Herbs Use in Treatment of Primary Dysmenorrhea (Menstrual Cramps). 2019.

41. Qasemi Dehkordi N, Qanadian M, S. S. Collection, identification and examining traditional use of a selection of regional herbs of Gardanerokh region in Chahar Mahal o Bakhtiari province. Iran and Islam Traditional Medicine. 2015;1:80-8.

42. Rajabzadeh F, Fazljou SM, Khodaie L, Abbasalizadeh S, Sahebi L. Effects of hot temperament herbs on primary Dysmenorrhea: a systematic review. World Family Medicine Journal: Incorporating the Middle East Journal of Family Medicine. 2018;99(5897):1-7.

43. Chauhan ES, Jaya A. Chamomile an Ancient Aromatic Plant-A Review. Journal of Ayurveda Medical Sciences. 2017;2.

44. Abedian Z, Rezvani fard M, Asili j, Esmaili H, Dadgar S. Comparison of the effect of chamomile and mefenamic acid capsules on postpartum hemorrhage in women with postpartum pain pain. Iranian Journal of Obstetrics, Gynecology and Infertility. 2016;19(14):1-8.full text in persian. 
45. Kermani NA. A Commentary on Al-Asabab and Al-Alamat, Research Institute of Rehabilitation of Natural Medicine: Jalaluddin Publications; 2008.

46. Jarjani SI. Save Kharazmshahi, edited by Saeed Sirjani, Publications of Iran Cultural Foundation.

47. Rahimi R, Shams Ardakani M R, Farjadmand F.Innovations and Experiences of the Wise Sayyid Muhammad Momen Tonekaboni in the Book of Gifts of the Faithful. Quarterly Journal of Traditional Medicine of Islam and Iran.2010; 1(2). (full text in Persian)

48. Yazdani M, Shahriari M, Hamedi B. Comparison of Fennel and Chamomile extract and placebo in treatment of premenstrual syndrome and dysmenorrheal. Hormozgan Medical Journal. 2004;8(1):5761.(full text in persian).

49. Dadfar F. Effectiveness of Chamomile (Matricaria chamomilla) extracts on the reduction of dysmenorrhea and premenstrual syndrome symptoms. Der Pharm Let. 2015;7(12):454-8.

50. Mirabi P, Alamolhoda SH, Esmaeilzadeh S, F M, . Effect of medicinal herbs on primary dysmenorrhoea.A systematic review. Iranian journal of pharmaceutical research: IJPR. 2014;13(3):75767.

51. Merfort I, Heilmann J, Hagedorn-Leweke U, et al. In vivo skin penetration studies of camomile flavones. Die Pharmazie. 1994;49(7):11-509.

52. Amsterdam JD, Shults J, Soeller I, al e. Chamomile (matricaria recutita) may have antidepressant activity in anxious depressed humans-an exploratory study. Alternative therapies in health and medicine. 2012;18(5):44.

53. Shabani F, Chabra A, Vakilian K, et al. Effect of Ginger-chamomile Sachet plus Honey on Primary Dysmenorrhea and Associated Symptoms: A Randomized, Double Blind, Controlled Trial. Current Women`s Health Reviews J. 2020.

\section{Figures}




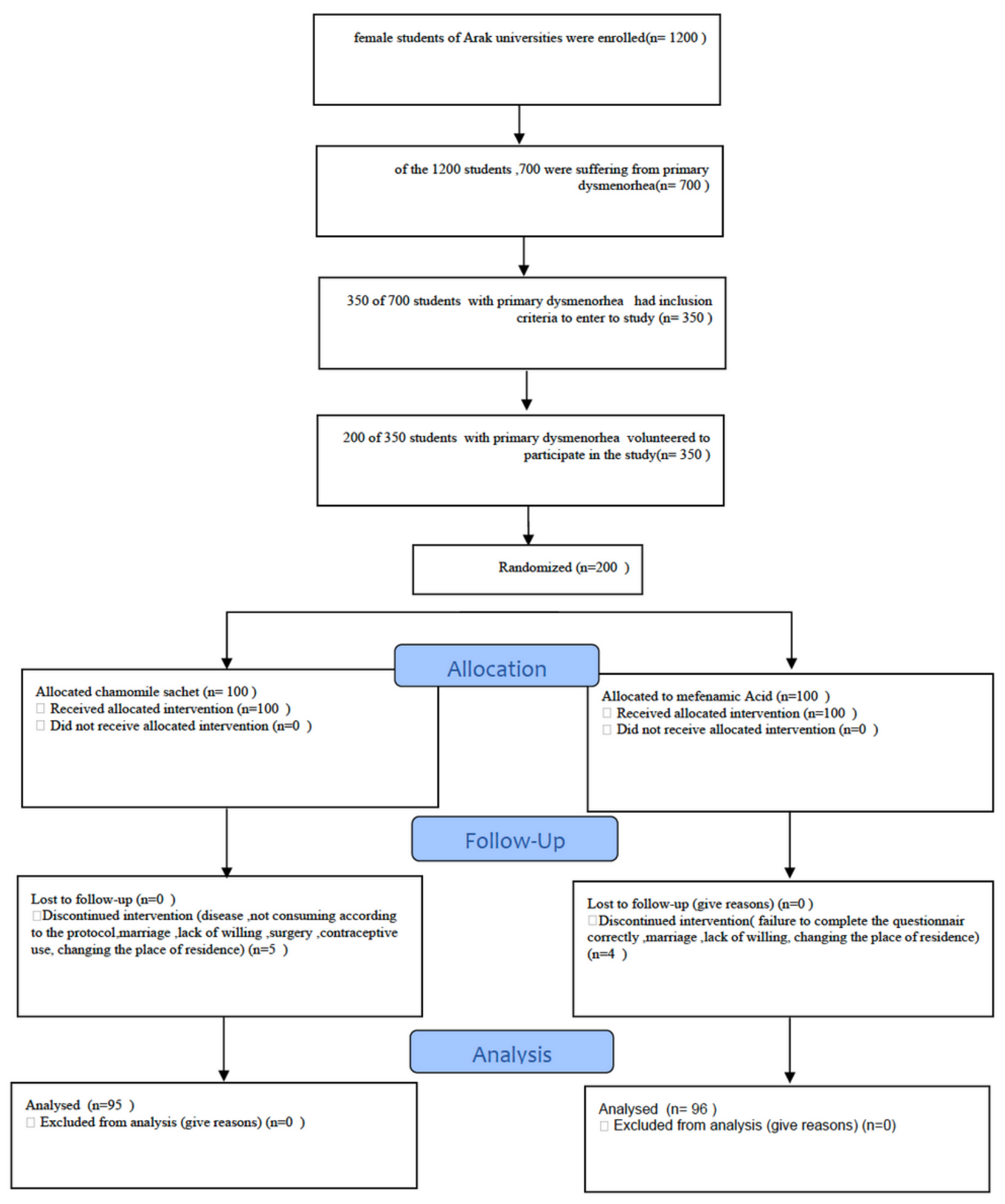

\section{Figure 1}

Consort Flow Diagram 